\title{
The role of social capital in the institutionalization of regional place marketing activity
}

\author{
Juha Halme ${ }^{1}$ (D) \\ Revised: 25 September 2020 / Accepted: 8 February 2021 / Published online: 1 March 2021 \\ (c) The Author(s) 2021
}

\begin{abstract}
This paper aims to study the outcomes of the regional level place marketing projects, which contribute towards the fruition of long-term place marketing or branding goals. It applies a theoretical framework based on institutional and social capital theories. Hence, it highlights the role of networks, norms of behavior and values, and trust regarding the institutionalization of regional place marketing activity. Two ERDF (European Structural Development Funding)-funded regional place marketing projects carried out in eastern Finland are explored. The empirical material consists of 23 semi-structured interviews of steering group members of the projects and documentary data on the later developments of the place marketing activity in the regions. The findings show that social capital generated during the projects contributed to the institutionalization of place marketing activity by reinforcing the will to do place marketing together, forming information-sharing practices, and expanding and strengthening stakeholder networks. Results indicate that social relations and structures that are formed during the place marketing collaborations can extend the lifespan of regional place marketing activity beyond short-lived projects, while there remains a need to develop this perspective into a measurable variable.
\end{abstract}

Keywords Social capital $\cdot$ Regional place marketing $\cdot$ Institutionalization $\cdot$ Inter-organizational collaboration

\section{Introduction}

A common way to implement place marketing or branding activity in European regions is through European structural fund (ERDF) projects. While these projects enable a strong financial incentive to trigger place marketing activity in the regions and engage local stakeholders, they have a limited lifespan that does not conform with the long-term goals of place marketing or branding such as improving the image of a place or constructing a place brand. In this regard, an important outcome of the project can be considered to be whether the projects have been able to develop structures and social relations that can sustain the place marketing activity after the projects have finished.

Literature has covered extensively the impact of the place marketing and branding activities on the places and target groups, from the marketing performance perspective (Witte and Braun 2015; Zenker and Braun 2015; Foroudi et al.

Juha Halme

juha.halme@uef.fi

1 Karelian Institute, University of Eastern Finland, Joensuu, Finland
2016; Rauhut and Rauhut Kompaniets 2020). However, outcomes of the collaborative processes between participants have not received enough attention, although recently the interactive and communicative dimensions have gained more traction (Stubbs and Warnaby 2015; Ripoll Gonzalez and Lester 2018; Halme 2020). Regarding such outcomes, in a recent study, Donner et al. (2017) mentioned that cooperation and network efficiency can be considered as a key success in the context of regional branding. To expand this argument and hence fill the gap in the literature, the purpose of this paper is to study the outcomes of the collaborative processes which can contribute towards the sustainability of the place marketing activity.

Towards this end, the study applies a theoretical lens drawn from the institutional and social capital theories. Firstly, the institutional theory understands the sustainability of the collaborative action through the concept of institutionalization, which in the context of this paper refers to practices and rules, that become embedded in the interaction between participants of the collaboration or have a broader impact on the organizational field (Lawrence et al. 1999, 2002; Phillips et al. 2000). Secondly, the study applies the social capital theory, which argues that institutionalization 
of the collaborative action is supported by the trust, norms of behavior, and networks, which are engendered during the collaboration (Innes et al. 1994; Wang and Xiang 2007; Dhillon 2009). This paper builds on a study of two regional level place marketing projects conducted in eastern Finland between 2011 and 2014, focusing on the institutionalization of place marketing activity through social capital building. The research question of the study is: How does the social capital engendered between participants of the place marketing projects lay foundations towards institutionalization of place marketing activity?

The paper contributes to the place marketing literature on the interactive and communicative aspects of stakeholder collaboration. Likewise, it accentuates the relevance of trust, networks, and norms of behavior which are engendered during the collaboration by adopting the social capital theory perspective. Furthermore, the study contributes to the literature on the impact of place marketing and branding activities. It argues that social relations and structures, which facilitate the institutionalization of place marketing and branding practices, should be taken as a major variable when evaluating the impact of the place marketing activity. Finally, the study presents good practices that can be applied to facilitate the institutionalization of the place marketing activity beyond short-lived projects. Specifically, it identifies the importance of strengthening the information-sharing networks and practices, confidential relations and trust, and the formation of contractual arrangements regarding funding and coordination of the place marketing activity. This facilitates the emergence of autonomous local-level place marketing practices, which are not dependent on external funding solutions, such as ERDF. This is a highly relevant matter in light of the global pandemic of 2020, which has considerably lowered the possibilities of external funding for local place marketing activities.

The study is structured as follows: In section "Theoretical framework" relevant literature is reviewed. Section "Main research approach" describes the main research approach followed by methodological considerations in section "Methodology". Then, empirical findings are presented in section "Key findings". Conclusions are drawn in section "Conclusion", and finally, practical implications are presented in section "Practical implications".

\section{Theoretical framework}

In the place marketing literature, the outcomes of place marketing and branding activities have been mainly addressed from the perspective of the impact which the activity has on the places and the target groups. Lucarelli (2012), for example, categorized the outcomes of the city branding into identity-image, socio-political and economic impacts which branding activities have on the cities, in his review of city branding literature. Instead, Zenker and Braun (2015), in their review of place branding measurements, identified that place branding measurements focus on either physical characteristic of a place, brand value driver, or brand equity for different target groups such as residents, tourists, investors/companies and media. In their recent review of different impact measurements, Rauhut and Rauhut Kompaniets (2020) concluded that many studies that try to measure the impact of the place marketing activities are based on ex ante/ex post comparisons, which do not theoretically try to address the reason why certain changes occur.

While it is true that the performance variables can provide important knowledge on the effectiveness of the place marketing and branding activities, they do not indicate its longevity, which has been considered as an essential element for the success of place marketing activity (Morgan et al. 2004; Anholt 2007; Kavaratzis and Ashworth 2008; Stubbs and Warnaby 2015). In this regard, place marketing literature has also addressed the outcomes that derive from the collaborative process between participating stakeholders, i.e., how the relations between participating organizations have developed or transformed during the collaborative action. For example, in a recent study by Donner et al. (2017), it was argued that cooperation and network efficiency can be considered as a key success in the context of regional branding, as they increase the autonomy of the region from foreign influence. This notion is corroborated with a broad range of inter-organization collaboration literature which argues that the outcomes of the collaborative action, such as place marketing projects, should be understood as more varied than performance variables (Hardy et al. 2003; Wang and Xiang 2007; Naipaul et al. 2009; Beritelli 2011; Clarke and MacDonald 2016). As illustrated above, the outcomes of the collaborative processes are an important element for the sustainability and long-term effectiveness of the place marketing and branding activity, but it is still under-researched phenomena in the place marketing literature. To address this gap, this study proposes a theoretical framework based on two key theories, which consider the relationship between the outcomes and the sustainability of a collaborative action: institutional theory and social capital theory.

Firstly, the sustainability of collaborative action has been discussed in the institutional theory, through the concept of institutionalization, i.e., the process by which institutions are produced and reproduced (Scott 1987). Drawing from the institutional theory Phillips et al. (2000) have claimed that the inter-organization collaboration is a potential site for institutionalization. An important mechanism through which this occurs is the formation of 'practices and rules' which become embedded in the ongoing interaction between participants, or as part of the wider organizational field after the collaboration has finished (Lawrence et al. 1999). Practices 
refer to the patterns of action that become legitimated and institutionalized within some context, while rules consist of normalized understanding of legitimate behavior manifested, for example, in contractual arrangements or legislation. The institutionalization of practices and rules is not an automatic process, but rather dependent on the motivation and capability of participating organizations: motivation refers to the will of an organization to change the practices and rules of the institutional field, whereas capability indicates the ability of the participant of the collaboration to institutionalize the rules and practices (Phillips et al. 2000; Lawrence et al. 2002).

Another theory that has addressed the sustainability of collaborative action is the social capital theory, which suggests that the sustainability of collaborative action is supported by the resources which are embedded within a network of relationships (Granovetter 1985). Social capital has been defined in various ways depending on the field of research. For example, Putnam (1994), has defined social capital as "features of social organization such as networks, norms, and social trust that facilitate coordination and cooperation for mutual benefit". A similar definition was applied by Dhillon (2013, 2015), who defined the dimensions of social capital as trust, networks, mutual goals, and shared norms and values. While the literature has emphasized the benefits of the social capital it has been also criticized on the ground of negative effects such as the exclusion of differing perspectives from a network with high levels of trust (Dhillon 2009), and concentration of power (Hardy et al. 2003).

Social capital has been understood in the literature as an important facilitator for the sustainability and institutionalization of collaborative action. For example, Innes (1994) has claimed that social capital in form of trust, norms of behavior, and networks of communication can be utilized beyond the collaboration, and in this sense facilitate institutionalizing long-term collaborative actions. Similarly, Wang (2007) has considered that social capital, such as relationships and trust between different sectors and organizations, may be applied as high-quality information, future project opportunities, and a spirit of collaboration in the place. In the same vein, Dhillon $(2009,2013)$ has found that social capital enhances the effectiveness and sustainability of partnerships in the context of education.

Although the institutional and social capital theories stem from different theoretical traditions, they illustrate two important dimensions that contribute towards the sustainability of a collaborative action: (1) the social structure (networks, norms, and trust), and (2) the recurring patterns of actions (practices and rules). Concerning the outcomes of collaboration, these two dimensions are not exclusive, but rather support each other: social capital in form of networks, norms of behavior and values, and trust contributes to the manifestation of practices and rules between participating organizations and hence contributes towards institutionalization of collaborative action. Therefore, these two theories provide a solid theoretical framework to understand the conditions for long-term collaborative action.

\section{Main research approach}

This paper follows the most-similar cases research design (Yin 2014), where two regional level place marketing projects were selected, due to their geographic proximity and similarity of organizational and financial background. The studied cases are located in eastern Finland, in adjacent regions of North Karelia (NK hereon) and Northern Savonia (NS hereon). These projects are titled: "Regional attractiveness program of North Karelia and Joensuu" of North Karelia (2011-2013) and the "Mission Future: Regional marketing program" of Northern Savonia (2012-2015). Both projects were funded by European Structural development funds (ERDF), which provided half of the funding for the projects, while participating organizations provided another half. Eastern Finland has been traditionally an economically weak area of Finland with high rates of unemployment and a rapidly aging population. In this regard, ERDF funding has been applied to develop physical infrastructure and promote economic growth, which projects at hand are examples of.

The project of NK was coordinated by the Regional Council of North Karelia, a regional development authority which has the duty by law to safeguard the regional interests and distribute EU funding. The project was preceded by two ERDF funded place marketing projects done by the Regional Council dating back to 1999. Place marketing activity in the region was originally initiated by Regional Council, and three sub-regional economic development organizations, which are all still represented in the project at hand. The project of NS was coordinated by the regional center of Kuopio (a city), which was a result of an agreement between the local Regional Council and the biggest cities. The project was the first regional-scale level place marketing project, which meant that there was no existing project framework. Earlier place marketing activity in the region of NS was more focused on destination marketing.

The main difference in the stakeholder assemblage between the two cases was that in NS local Regional Council was not represented in the project, other than as a funder. In this regard, many local municipalities and cities had direct representation in the project of NS. Otherwise, stakeholders in both projects stemmed from the educational sector, social- and health care sector, private companies, and economic and tourism development organizations. These organizations participated in the funding, managing, and providing material for the activities of the projects. Participating 
organizations were represented in the steering and executive groups of the projects. The steering groups were selected as the main source of data collection, as the participants were high-level representatives of participating organizations, which were assumed to have broad oversight of the place marketing activity in the region. The function of the steering groups was officially advisory, but in practice, as pointed out by the project managers, they had strong strategic responsibility in steering the decision-making in the projects.

\section{Methodology}

Collected data consist of 23 semi-structured interviews done with the steering group representatives of the projects in 2015. The semi-structured interviewing was selected as the data collection method, for its function of collecting insights into the participating organization's views on the outcomes of the projects (Gray 2004, pp. 215-216). Also, supplemental documentary data were collected concerning the later development of the place marketing activity in the regions to confirm the statements presented in the interviews. Specifically, this included planning documents of the forthcoming projects, which were addressed by the interviewees. Interview questions related to the outcomes and the future of place marketing activity in the region. These questions were formed as a result of preliminary interviews with the project managers. Interviews lasted from $30 \mathrm{~min}$ to $1 \mathrm{~h}$, and interviewees were given the possibility to read interview questions before the interviews.

The analysis of the interviews involved transcribing the interviews and coding of the sections in which representatives expressed their perspectives on the outcomes of the projects and their further plans on participating in the regional place marketing activity. Transcribing and coding were done by utilizing a CASDAQ (computer-assisted qualitative data analysis software) package TAMS (text markup system), which allows the hierarchical coding of the transcribed data (Weinstein 2006). The coding scheme was built by drawing from the concepts introduced in the theoretical framework of the study. Hence, attention was paid to the passages where representatives addressed the outcomes of the projects by referring to the forms of social capital such as networks, norms of behavior and values, or trust. Finally, analytical themes, described in the following section, were formed on basis of the frequency of the codes.

\section{Key findings}

In the following section, the findings of the analysis are presented. The focus is placed on the accounts of the interviewees that elaborated on the role of social capital in the institutionalization of practices and rules in the regions. Findings are divided into two main sub-sections. The first one includes the norms of behavior and values, and the second one the networks and trust.

\section{Norms of behavior and values}

The social capital in the form of values manifested in the projects of NK and NS through the perception of the value of continuing the place marketing activity together in the regions, and the collaborative practices which extended beyond the projects.

\section{Will of continuing the place marketing activity}

Firstly, concerning the values, the will of continuing the place marketing in the region was strengthened in both cases. In the case of NS, where the project was a first regional level place marketing project, representatives expressed strong motivation to continue participating in the activity. This was highlighted, for example, by the representative of the educational sector from NS:

(excerpt 1) It has not finished [place marketing], and it cannot be finished. Constructing a brand, and doing marketing is continuous work. It cannot be a project which ends and then the whole matter is forgotten. It will be pretty soon eroded brand like that.

Similarly, in the case of NK, while the project did not have direct continuation, the general sentiment of the representatives was that there is a need to continue the place marketing activity in the region. This was underlined by the representative of the economic sector:

(excerpt 2) That is the basic dilemma, that this [place marketing] has to be done because well, a place where nobody hears from, is dead.

Indeed, while there was no one uniting project, the representatives underlined the importance of continuing doing place marketing together, which was expressed by the representative of the economic sector:

(excerpt 5) One (of the outcomes) that was fulfilled is that we saw that, yes, these things have to be done together, and in a way, the thoughts and practices (between partners) are now more familiar, and that is a good base [to continue things].

\section{Continuation of collaborative practices}

Two cases had a different trajectory through which the place marketing activity was continued in the regions. In NK there was no direct continuation for the project at hand. However, 
different projects were being planned by participating organizations. The continuation of regional place marketing activity was elaborated by the representative of the regional center, who emphasized that in the future the place marketing activity would be done not through big projects, but rather more exact measures:

(excerpt 6) Interviewer: So, there is a will to continue [place marketing activity]? Yes, definitely, but in a different form. That is, we don't invest all [resources] in a big mammoth. This gives the possibility to react according to the situation inside projects. This does not mean that we are quitting, and disbanding, this is not the matter here.

Representatives considered that these multiple planned projects benefited from the collaborative practices which were developed along with the current project and extended beyond. This was noted by the representative of the regional center of NK:

(excerpt 7) One of the successes [of the project] has been that we are currently in a situation, where we can move forward with a different type of project because stakeholders have already established collaborative practices in certain things, they are never good enough, and there is always room for development, but they are better than four years ago.

More specifically, these practices are related to the exchange of information between participants. Representatives mentioned that after the project, the steering group members continued to have meetings where participants could share information regarding their current activities. This was elaborated by the representative of the educational sector from NK:

(excerpt 8) The project has finished, but we still meet [with the steering group members], and tell each other what we are doing, and see what we can do together. Nothing else has been changed in the place marketing expect the project funding. Now we don't gather the money first, but rather the people meet, and see what we should do together.

In the case of NS, the continuation of place marketing activity was secured through individual funding contracts with participating organizations and was coordinated by the regional center of Kuopio. This was elaborated by the municipal representative:

(excerpt 3) Now the [tasks of the project] emerge as part of the organization of the regional center of Kuopio, and the city does partnership contracts regarding the continuation. It will be kind of outsourcing service, that we will buy certain marketing services.
This form of contractual continuation of the project was also considered to secure the engagement of the stakeholders, which was addressed by the representative of the educational sector:

(excerpt 4) Now we are doing the general agreements with [participating] organizations. I kind of see, that when we are doing these agreements, where organizations invest money, then I would suppose that who are involved with this, are highly engaged.

\section{Expanding and strengthening of the networks}

The second main form of social capital that was identified in the cases at hand related to the networks which were expanded and strengthened during the projects, and which further contributed towards institutionalization of place marketing activity in the regions.

\section{Expanding the networks}

Two studied cases had a different premise regarding the networks. In the case of NS, the project at hand was the first large scale effort in regional place marketing, and there was no existing network between participants. Indeed, many representatives highlighted that the important outcome of the project was finding new partners during the project. For example, a representative of the educational sector brought this up:

(excerpt 9) If we think that previously we did jointmarketing with the actors from Upper Savonia [subregion in NS], then now we have found more partners ... that is sort of a network. Always when there are new people in the table, there are also new thoughts, and it makes it possible to create new ideas, and in that way facilitate things.

As a result of being able to create a network with new partners, representatives in the case of NS considered that the project enabled participants to understand the organizational field of the region from a broader perspective. This was addressed by the representative of the economic sector:

(excerpt 10) We have a better common understanding of the regional strengths, that we do not only look from the perspective of one municipality, but we could see better the bigger picture because there is a lot of variety in the businesses around the region ... we can see better the whole picture, instead of having a limited view.

Representatives addressed, that the formation of the networks was based on trust and confidential relations between participants. This was not considered as a taken-for-granted 
matter, but rather an effort which takes considerable time, as accentuated by the representative from the municipal sector from NS:

(excerpt 11) When this [the project] continues, in one way or another, if we got to know partners during the project, who will stay, then maybe in the future there will be more [partners]. It always takes a lot of time to form this kind of confidential collaborations, and to find partners.

\section{Strengthening the networks}

Unlike the case of NS, in NK there had been already a succession of three regional place marketing projects carried out by the same coordinator, and many participating organizations had already established a stable network and confidential relations between them. The representative of the economic sector highlighted these existing networks, and considered that the current project further strengthened them:

(excerpt 12) Of course, it is valuable that we have discussion connection, and that we have learned things from each other, it has been achieved. It already existed before the project, but the project deepened it.

The established network between stakeholders appeared to have large significance for the participants of the collaboration. For example, representative of the educational sector pointed out that one reason for their participation in the project was the access to this network, and the importance of being in the same table with other educational organizations, for the sake of political balance between organizations in the region:

(excerpt 13) We are ready to pay, that we are in the same table with others ... there happens also other interactions [than the matters of the project]. Interviewer: That is, kind of networking? Yes, that collaboration has a small price tag

Representatives in NK found that the project did strengthen the informal networks among participants, nevertheless, some representatives considered that this was not a sufficient solution for the future coordination of the place marketing activity in the region and called out for more clear procedures for continuation. This was emphasized by the representative of the economic sector:

(excerpt 14) For me, the full completion of the aims of the project would have meant that there would have lived on a practice by Regional Council, or whoever it is, that there is a person $\mathrm{x}$ that gathers people together, that once in a year we do together a common marketing effort ... that we have a clear procedure.
This point was further confirmed by the representative of the regional center of NK who explained that there was no sufficient continuity between the successive projects:

(excerpt 15) Between the projects, there was a critique from almost all [participants]. Once the one [project] has finished, the new one starts. There was not enough from where to continue, that is, what was already done, and what was developed. Pretty easily we start to build things again, which have been already once thought out.

\section{Conclusions}

Project-based place marketing activity is by its nature shortlived and generally fails to meet the long-term place marketing aims such as improving the image of a place or developing a place brand. In this regard, an important outcome of the project-based place marketing can be considered whether the projects have been able to develop structures and social relations that can sustain the place marketing activity after the projects have finished. Place marketing literature has addressed the importance of such outcomes (Donner et al. 2017) but has not so far explored these outcomes neither in empirical nor theoretical level. To fill this gap in the literature, this paper applies insights from two theories that have addressed the sustainability of collaborative action: social capital and institutional theory. Hence, it brings attention to the relevance of the social structure (networks, norms of behavior and values, and trust), and the recurring patterns of actions (practices and rules), in building a long-term place marketing activity.

The findings from the study of two regional level projects demonstrated that social capital that was generated during the projects contributed towards the institutionalization of place marketing activity in the regions. Firstly, social capital facilitated institutionalization by reinforcing the value of doing the place marketing together in the regions also in the future. Secondly, it brought forth collaborative practices, such as information-sharing between participants, which carried over beyond the projects at hand. These were further supported by the development of the set of marketing tools that could be applied in future place marketing activities. Thirdly, social capital supported institutionalization through expanding and strengthening the networks between participating organizations. The expansion of networks and forming trust-based confidential relations between participants was considered important especially in the case of NS, where the project was the first regional-scale place marketing project.

While the strengthening of the networks between participants was also considered an important outcome in the 
project of NK, the participants argued that there would have been a need to administer a clear distribution of responsibilities for coordinating future place marketing activities in the region. This underlined the significance of rules, such as contractual arrangements, as another key aspect of the institutionalization of the collaborative action. In the case of NS, such rules were put into place through individual funding contracts with participating organizations, which secured funding and engagement of them for the place marketing activity in time after the project.

\section{Practical implications}

This study has several practical implications for place marketing practice and theory. Firstly, the study identified good practices that can be applied to extend the lifespan of the place marketing activity beyond short-lived projects, or other temporary organizational formations, and contribute towards the fruition of long-term place marketing goals, such as improving the image of a place or building a place brand. By drawing from social capital theory, the study underlines the importance of straightening the information-sharing networks and practices and confidential relations and trust between participating organizations in the projects. Findings illustrate the relevance of these forms of social capital towards the institutionalizing place marketing practices and building ground for new collaborative possibilities. The relevance of social capital for the institutionalization of place marketing practices is evident; however, the findings also suggest that formal rules, such as contractual arrangements, and formal distribution of duties on the coordination of place marketing activities, have a central role in supporting the institutionalization process. These are important considerations especially for places where the institutionalization of place marketing activities is in the early stages.

Secondly, while the place marketing literature has advanced the knowledge on the performance variables of place marketing and branding activity, the research on the social outcomes of the collaborative processes is still lacking. By underlining the importance of social capital for the institutionalization of the place marketing activity, the study contributes to interactive and communicative approaches that have emerged in the recent place marketing and branding literature (Stubbs and Warnaby 2015; Ripoll Gonzalez and Lester 2018; Halme 2020). Additionally, it contributes to the discussion on the impact of the (especially project-based) place marketing activity, by arguing that the development of structures and social relations which can sustain the activity after the projects have finished should be taken as a key variable when evaluating the impact of the place marketing activity. This study provides a theoretical groundwork for the development of this type of variable.
Further elaboration of such measurable variables should be addressed in future studies.

Thirdly, while this study addressed the issue of the outcomes of the collaboration between in-region stakeholders that were directly involved in the management and financing of the projects, nevertheless, it should be noted that the concept of 'stakeholder' in the place marketing context should be understood as a broader category covering, for example, the citizens of the places who have a direct stake in the matter. In this regard, the future study interested in the institutionalization of the place marketing practices should pay attention to the issue of maintaining the engagement of the citizens in long-term place marketing and branding activity.

Funding Open access funding provided by University of Eastern Finland (UEF) including Kuopio University Hospital.

\section{Compliance with ethical standards}

Conflict of interest The author states that there is no conflict of interest.

Open Access This article is licensed under a Creative Commons Attribution 4.0 International License, which permits use, sharing, adaptation, distribution and reproduction in any medium or format, as long as you give appropriate credit to the original author(s) and the source, provide a link to the Creative Commons licence, and indicate if changes were made. The images or other third party material in this article are included in the article's Creative Commons licence, unless indicated otherwise in a credit line to the material. If material is not included in the article's Creative Commons licence and your intended use is not permitted by statutory regulation or exceeds the permitted use, you will need to obtain permission directly from the copyright holder. To view a copy of this licence, visit http://creativecommons.org/licenses/by/4.0/.

\section{References}

Anholt, Simon. 2007. Competitive Identity: The New Brand Management for Nations, Cities and Regions. London: Palgrave Macmillan.

Beritelli, Pietro. 2011. Cooperation Among Prominent Actors in a Tourist Destination. Annals of Tourism Research 38 (2): 607-629.

Clarke, A., and A. MacDonald. 2016. Outcomes to Partners in Multistakeholder Cross-Sector Partnerships: A Resource-Based View. Business \& Society 58: 1-35.

Dhillon, Jaswinder K. 2009. The Role of Social Capital in Sustaining Partnership. British Educational Research Journal 35 (5): 687-704.

Dhillon, Jaswinder K. 2013. Senior Managers' Perspectives of Leading and Managing Effective, Sustainable and Successful Partnerships. Educational Management Administration \& Leadership 41 (6): 736-750.

Dhillon, Jaswinder K. 2015. Social Capital in Inter-Organizational Partnership Research. In Handbook of Research Methods and Applications in Social Capital, ed. Yaojun Li. Cheltenham: Edward Elgar Publishing.

Donner, Mechthild, Lummina Horlings, Fatiha Fort, and Sietze Vellema. 2017. Place Branding, Embeddedness and Endogenous 
Rural Development: Four European Cases. Place Branding and Public Diplomacy 13 (4): 273-292.

Foroudi, Pantea, Suraksha Gupta, Philip Kitchen, Mohammad M. Foroudi, and Bang Nguyen. 2016. A Framework of Place Branding, Place Image, and Place Reputation. Qualitative Market Research: An International Journal 19 (2): 241-264.

Granovetter, Mark S. 1985. Economic Action and Social Structure: The Problem of Embeddedness. American Journal of Sociology 91 (3): 481-510.

Gray, David E. 2004. Doing Research in the Real World. London: SAGE Publications.

Halme, Juha. 2020. Constructing Consensus and Conflicts. Qualitative Market Research: An International Journal 23 (4): 961-978.

Hardy, Cynthia, Nelson Phillips, and Thomas B. Lawrence. 2003. Resources, Knowledge and Influence: The Organizational Effects of Interorganizational Collaboration. Journal of Management Studies 40 (2): 321-347.

Innes, Judith, Judith Gruber, Michael Neuman, and Robert Thompson. 1994. Coordinating Growth and Environmental Management Through Consensus Building. 270 pp.

Kavaratzis, Mihalis, and Gregory Ashworth. 2008. Place Marketing: How Did We Get Here and Where Are We Going. Journal of Place Management and Development 1 (2): 150-165.

Lawrence, Thomas B., Cynthia Hardy, and Nelson Phillips. 2002. Institutional Effects of Interorganizational Collaboration: The Emergence of Proto-Institutions. Academy of Management Journal 45 (1): 281-290.

Lawrence, Thomas B., Nelson Phillips, and Cynthia Hardy. 1999. Watching Whale Watching: Exploring the Discursive Foundations of Collaborative Relationships. The Journal of Applied Behavioral Science 35 (4): 479-502.

Lucarelli, Andrea. 2012. Unraveling the Complexity of 'City Brand Equity': A Three-dimensional Framework. Journal of Place Management and Development 5 (3): 231-252.

Morgan, N., A. Pritchard, and R. Pride, eds. 2004. Destination Branding: Creating the Unique Destination Proposition. Oxford: Elsevier Butterworth-Heinemann.

Naipaul, Sandra, Youcheng Wang, and Fevzi Okumus. 2009. Regional Destination Marketing: A Collaborative Approach. Journal of Travel \& Tourism Marketing 26 (5-6): 462-481.

Phillips, Nelson, Thomas B. Lawrence, and Cynthia Hardy. 2000. InterOrganizational Collaboration and the Dynamics of Institutional Fields. Journal of Management Studies 37 (1): 23-43.

Putnam, Robert D., Robert Leonardi, and Raffaella Y. Nanetti. 1994. Making Democracy Work. Princeton: Princeton University Press.
Rauhut, Daniel, and Olga Rauhut Kompaniets. 2020. How to Measure the Impact of Place Marketing Activities: A Methodological Discussion. GeografiskTidsskrift-Danish Journal of Geography 120 (1): 67-78.

Ripoll Gonzalez, Laura, and Libby Lester. 2018. 'All for One, One for All': Communicative Processes of Co-Creation of Place Brands Through Inclusive and Horizontal Stakeholder Collaborative Networks. Communication \& Society 31 (4): 59-78.

Scott, W. Richard. 1987. The Adolescence of Institutional Theory. Administrative Science Quarterly 32 (4): 493-511.

Stubbs, Julian, and Gary Warnaby. 2015. Rethinking Place Branding from a Practice Perspective: Working with Stakeholders. In Rethinking Place Branding: Comprehensive Brand Development for Cities and Regions, ed. M. Kavaratzis, G. Warnaby, and G. Ashworth, 101-118. Cham: Springer.

Wang, Youcheng, and Zheng Xiang. 2007. Toward a Theoretical Framework of Collaborative Destination Marketing. Journal of Travel Research 46 (1): 75-85.

Weinstein, Matthew. 2006. TAMS Analyzer. Social Science Computer Review 24 (1): 68-77.

Witte, Jan-Jelle., and Erik Braun. 2015. Cross-Border Place Branding in Europe. In Inter-Regional Place Branding, ed. Sebastian Zenker and Björn. P. Jacobsen, 87-98. Cham: Springer.

Yin, Robert K. 2014. Case Study Research: Design and Methods. Los Angeles: SAGE.

Zenker, Sebastian, and Erik Braun. 2015. Rethinking the Measurement of Place Brands. In Rethinking Place Branding, ed. M. Kavaratzis, G. Warnaby, and G. Ashworth, 211-223. Cham: Springer.

Publisher's Note Springer Nature remains neutral with regard to jurisdictional claims in published maps and institutional affiliations.

Juha Halme works as a project researcher at the Karelian Institute, University of Eastern Finland. He recently defended his doctoral dissertation on the discursive dynamics in stakeholder collaboration in regional-level place marketing projects. His academic interests include inter-organizational collaboration, qualitative methods, and discourse theory. His previous work has been presented at various international conferences and published in journals, such as Environment and Planning C: Politics and Space, Qualitative Market Research, and Journal of Place Management and Development. 